\title{
hCG Uygulamasından 36 Saat ile 42 Saat Sonra Yapılan İntrauterin İnseminasyonların Klinik Sonuçlarının Karşılaştırılması
}

Comparison of Clinical Outcomes of Intrauterine Inseminations which Performed at 36 Hours Versus 42 Hours After hCG Trigger

\section{Samettin ÇELIK ${ }^{1}$, Banuhan ŞAHİN ${ }^{2}$, Aysemin GÜRÇAĞLAR ${ }^{2}$, Canan Soyer ÇALIŞKAN ${ }^{1}$ Şafak HATIRNAZ ${ }^{3}$}

1. Samsun Eğitim ve Araștırma Hastanesi, Kadın Hastalıkları ve Doğum Kliniği, Samsun, Türkiye

2. Amasya Üniversitesi Sabuncuoğlu Şerefeddin Ĕgt. ve Arş. Hast., Kadın Hastalıkları ve Doğum Anabilim Dalı, Amasya, Türkiye 3. Samsun Medicana Hastanesi, Samsun, Türkiye

\section{$\ddot{O Z Z T}$}

Amaç: Intrauterin inseminasyon (IUI), infertil çiftlerin gebelik şansını artırmak için yaygın olarak kullanılan bir işlemdir. hCG (human koryonik gonadotropin) uygulamast sonrasi planlanan IUI zamanlaması pratikte 36. Saat olarak belirlenmiştir. Ancak klinik yoğunluk sebebi ile bu zamanlamada gecikmeler yaşanabilmektedir. Biz de çalışmamızda IUI'ları 36. Saate ve 42. Saate yapılan hastaların klinik sonuçlarını karşılaştırmayı amaçladık.

Gereçler ve Yöntem: Samsun Ĕ̈itim ve Araștırma Hastanesine açılanamayan infertilite sebebi ile başvurmuş ve gonadotropin tedavisi sonrası IUI yapılmıș 450 hastanın kayıtları geriye dönük incelendi. Klinikteki yoğunluk sebebi ile hCG uygulamasi sonrasi IUI zamanlamasi 6 saat gecikmiş (42. Saat) olan hastalar ile zamaninda (36. Saat) yapılmis hastaların demografik bilgileri, hormon düzeyleri, endometrium kalınlıkları, toplam folikül sayıları, $\beta$-hCG test pozitiflikleri, canlı doğum oranları ve spontan abort oranları değerlendirildi. Gruplar arası karşılaştırmalarda Student t test ve Ki-kare testi uygulandl.

Bulgular: Hastaların 348 'ine IUI prosedürü hCG uygulamast sonrasında 36. Saatte uygulanmışken 102 'sine 42. Saatte uygulanmıştı. Gruplar arasında yaş, infertilite süresi, bazal hormon düzeyleri ve endometrial kalınlıklar açısından fark izlenmedi $(p<0.05)$ (Tablo 1). IUI tedavilerinin gebelik sonuçları üzerine olan etkileri incelendiğinde gruplar arasinda ovulasyon indüksiyonu sonrası elde edilen dominant folikül sayıları, $\beta$ - $h C G$ test pozitiflikleri, canlı doğum oranlart ve spontan abortus oranlar açısından fark görülmedi ( $p=0.34, p=0.12, p=0.31, p=0.25$ ) (Tablo 2).

Sonuç: hCG enjeksiyonu ile tetiklenen ovulasyonun ardından IUI zamanlamasl 42. saate geciktirilen hastaların klinik gebelik oranları 36. Saatte IUI yapılanlara göre değişmemektedir.

Anahtar Kelimeler: infertilite, intrauterin inseminasyon, canl doğum

\section{ABSTRACT}

Objective: Intrauterine insemination (IUI) is a commonly used procedure to increase the chance of pregnancy in infertile couples. The planned IUI timing after hCG (human chorionic gonadotropin) trigger was practically determined as at 36th hour. However, this timing may be delayed due to clinical traffic. In our study, we aimed to compare the clinical results of patients who underwent IUIs at 36 th hour versus at 42 nd hour.

\section{İletişim}

Sorumlu Yazar: Banuhan ŞAHIN

Adres: Amasya Üniversitesi Sabuncuoğlu Şerefeddin Eğt. ve Arşt. Hastanesi, Kadın Hast. ve Doğum Anabilim Dalı, Amasya, Türkiye Tel: +90 (506) 9264474

E-Posta: banuhansahin@gmail.com

Makale Geliș: 17.05.2019

Makale Kabul: 29.08.2019

DOI: http://dx.doi.org/10.16948/zktipb.566761
Material and Methods: The records of 450 patients who were admitted to Samsun Training and Research Hospital due to unexplained infertility and were performed IUI after gonadotropin treatment, were retrospectively analyzed. Demographic information, hormone levels, endometrial thickness, total follicle numbers, $\beta$-hCG test positivity, live birth rates, and spontaneous abortion rates of patients with 6 hours delay (42 hours) in IUI timing after hCG trigger due to the traffic in the clinic, and patients with on the time (36 hours) IUI performation were evaluated. Student's t-test and Chi-square test were used for comparisons between groups.

Results: IUI procedures were applied to 348 patients at the 36 th hour and 102 patients at the 42nd hour after the hCG triggers. No difference was observed between the groups in terms of ages, infertility durations, basal hormone levels and endometrial thicknesses $(p<0.05)$ (Table 1). When the effects of IUI treatments on pregnancy outcomes were examined, there was no difference between groups in terms of dominant follicle numbers obtained after ovulation induction, $\beta-h C G$ test positivity, livebirth rates and spontaneous abortion rates. $(p=0.34$, $p=0.12, p=0.31, p=0.25$ ) (Table 2).

Conclusion: The clinical pregnancy rates of patients with IUI timing after ovulation induced by hCG injection does not change with delaying to 42 nd hour versus 36 th hour.

Keywords: infertility, intrauterine insemination, livebirth

\section{GíRiş}

İntrauterin inseminasyon (IUI) özellikle açıklanamayan infertilitesi olan çiftlere uygulanan pratik, ucuz ve az invaziv olan bir tedavi yöntemidir (1). Kontrollü ovaryan hiperstimulasyon sonrası uygulanan IUI'lerde siklus başına \%10-20 kinik gebelik oluşmaktadır (2). IUI'de gebelik elde etme başarısı maternal yaş, ovarian stimülasyon (OS) protokolleri, sperm parametreleri ve IUI uygulamaları gibi çeşitli faktörlere bağlıdır (3). En çok tartışılan konulardan biri, insan koryonik gonadotropin (hCG) enjeksiyonu sonrası yapilacak olan inseminasyonun zamanlamasıdır. Her ne kadar hCG enjeksiyonundan 34-38 saat sonra inseminasyon uygulamas1 günümüz pratiğinde en yaygın şekilde kullanılsa da bu zaman aralığı için klinik kanıt azdır (4). Uyarılmıș sikluslarda ovulasyonun hCG uygulamasından yaklaşık 36 saat sonra gerçekleştiği bilinmektedir (4). Bununla birlikte, gonadotropin (GND) ile yapılan OS'ların \%20'sinde luteinize edici hormon (LH) erken dalgalanması meydana gelmektedir ve bazı oositler hCG enjeksiyonundan 12 saat sonra fertilize olabilmektedir (5). 
IUI sikluslarında gebelik oranlarını artırmak için farklı inseminasyon zamanlamaları önerilmiştir. Jarvela ve arkadaşları hCG'den hemen sonra IUI uygulandığında gebelik oranlarını, hCG'den 24-32 saat sonra IUI uygulamasına göre daha yüksek bulmuşlardır (6). Aydın ve arkadaşları ise hCG enjeksiyonu ile eş zamanlı IUI'lar ile hCG enjeksiyonundan 34-36 saat sonra yapılan IUI'ler arasında klinik gebelik oranlarının değişmediğini savunmuşlardır (7). Tonguç ve arkadaşları hCG'nin 24. Saatinde yapılan IUI'larda gebelik oranlarının 36. Saatte IUI yapılanlardan ve $12+36$. Saatte çift IUI yapılanlardan düşük olmadığını, tatil gibi kaçınılmaz gecikmeler nedeniyle siklusun iptal edilmemesine yönelik uygulanabileceğini öne sürmüşlerdir (8).

Çeliş̧kili sonuçlara rağmen, hCG uygulamasindan yaygin olarak 36-38 saat sonra inseminasyon uygulanmaktadır, ancak bu pencerenin ne kadar geciktirilebileceği hakkında yeterli kanıt yoktur. Klinik pratikte gün içerisindeki yoğun iş trafiği nedeni ile inseminasyon zamanlamasinda gecikmeler yaşanabilmektedir. Biz de bu çalışmada IUI'si 36. Saatte yapılan ve 42 . Saatte yapılan hastaların klinik sonuçlarını karşılaştırmayı amaçladık.

\section{GEREÇ ve YÖNTEM}

Samsun Eğitim ve Araştırma Hastanesi kadın hastalıkları ve doğum polikliniklerine 2017-2018 yıllarında açıklanamayan infertilite sebebi ile başvurmuş 450 kadın çalışmaya dahil edildi. Hasta dosyaları geriye dönük incelendiğinde her hastaya tek IUI protokolü uygulanmış olduğu görüldü. Açıklanamayan infertilite, Dünya Sağlık Örgütü 2010 kriterlerine göre normal uterin kavite, en az bir sağlam tuba-over döngüsü ve normal semen parametrelerine sahip vakalar olarak tanımland. Tüm hastalarda inseminasyondan önce en az bir fallop tüpünün açıklığını doğrulamak için histerosalpingografi yapılmıştı. Tüm hastalara recombinant FSH (Folikül stimüle edici hormon) ile ovulasyon indüksiyonu uygulanmıştı ve en az iki folikülün $18 \mathrm{~mm}$ veya üzeri gelişim gösterdiği seri yapılan TVUSG ile konfirme edilmişti. IUI uygulamaları 348 kadına hCG uygulamasinın 36. Saatinde, 102 kadina ise 6 saat gecikmiş olarak yani hCG uygulamasının 42 . Saatinde yapılmıștı.

Endometriozisi olanlar, eşlik eden hastalıklar1 olanlar ve hormonal düzensizliği olanlar çalışma dıș bırakıldı. Ayrıca, üçten fazla $18 \mathrm{~mm}$ folikülü olanlarda ovaryan hiperstimülasyon ve çoğul gebelik oluşma riski nedeniyle IUI uygulamaları iptal edilmişti. Çiftler çalışma hakkında bilgilendirildi ve yazılı onamları alındı. Bu çalışmaya, doğası gereği retrospektif olmasına rağmen, 37-2019BADK/8-69 numarasıyla, hastane etik kurul onayı alınmıştır.

Çalıșmaya dahil edilen tüm kadınların yaşlar1, infertilite süreleri (y1l), menstruasyonun 3. günü FSH, LH, E2 (Östradiol), prolaktin, TSH (Troid stimüle edici hormon) değerleri ve endometrium kalınlıkları kaydedildi. Her iki grupta toplam folikül sayıları, $\beta$-hCG test pozitiflikleri, canlı doğum oranları ve spontan abort oranları değerlendirildi.

Tüm hastalara siklusun üçüncü gününden başlayarak her gün 75-150 uluslararası birim (IU) rekombinant foliküler uyarıcı hormon (r-FSH) (Gonal-f,Merck Serono,Switzerland) subkutan olarak uygulandi. Hastalar foliküler monitörizasyon için 7. ve 10. günlerde çağırıldı. Gonadotropin ile uyarım, dominant folikülün $17 \mathrm{~mm}$ 'ye ulaşmasına kadar devam etti ve IUI'den 36 saat önce tek bir rekombinant hCG (Ovitrelle, Merck Serono, İsviçre) 250 mikrogram dozunda subkutan olarak uygulandi.

IUI'den 1 saat önce eşlerden üç günlük cinsel perhiz sonrası mastürbasyonla semen materyalleri topland1. Semen örnekleri WHO 2010 kriterlerine göre analiz edildi (9). Sperm, iki tabakalı yoğunluk gradyanı (\%80 ve \%100) ayırma tekniği (Puresperm; Nydacon) ile hazırlandı ve vücut sıcaklığında hastaneye transferi sağlandı.

IUI ayaktan tedavi ünitesinde uygulandı. Steril bir spekulum kullanılarak serviks izlendi ve izotonik solüsyonla temizlendi. Servikal kanaldan yumuşak bir IUI kateteri (Set TDT; Fertitech Canada Inc.) yerleştirildi ve hazırlanan sperm kateter içinden 60 saniye içinde enjekte edildi ve 5 saniye beklenip kateter çekildi. Yirmi dakika yatak istirahati uygulandi.

Vajinal progesteron $100 \mathrm{mg}$ (Progestan tablet, Koçak Farma, İstanbul, Türkiye) günde üç kez vajinal yoldan luteal destek olarak başlandı. Gebelik sonuçlarını değerlendirmek için IUI işleminden 15 gün sonra B-hCG için kan testi önerildi. Klinik gebelik, ultrasonografi ile uterus kavitesinde kalp atışı olan fetüs tespiti olarak tanımland.

İstatistiksel analiz: Çalışmadaki veriler, Windows v 22.0 için IBM SPSS Statistics kullanılarak analiz edildi (IBM Corp, Armonk, NY). Tablolarda, nicel veriler ortalama $\pm \mathrm{SD}$, kategorik veriler sayı (n) ve yüzde (\%) olarak sunulmuştur. Bağımsız grupları karşılaştırmak için Student's t testi ve kategorik değișkenleri karşılaştırmak için Pearson ki-kare testi kullanılmıştır. Veriler \%95 güven düzeyinde belirlendi ve $p<0,05$ değeri istatistiksel olarak anlamlı kabul edildi.

\section{BULGULAR}

Hastaların 348'ine IUI prosedürü hCG uygulamas1 sonrasında 36. Saatte uygulanmışken 102 'sine 42. Saatte uygulanmıştı. Grupların demografik verileri, bazal hormon düzeyleri ve endometrial kalınlıklarının karşılaştırılması Tablo 1'de gösterilmiştir. Her iki grupta da yaş ortalaması 29 yıl, infertilite süresi 6 yildı. Gruplar arasinda serum bazal FSH, LH, E3, PRL, TSH değerleri ve endometrial bazal ölçümlerinde farkl1l1k izlenmedi $(\mathrm{p}=0.876, \mathrm{p}=0.098$, $\mathrm{p}=0.687,0.366, \mathrm{p}=0.733, \mathrm{p}=0.055)$.

Tablo 1: Hastaların demografik bilgileri, bazal hormon düzeyleri ve endometrial kalınlık değerleri.

\begin{tabular}{|l|l|l|l|}
\hline & $\begin{array}{c}\text { IUI 36. saatte } \\
(\text { say1 }=348)\end{array}$ & $\begin{array}{c}\text { IUI 42. saatte } \\
(\text { say1 }=102)\end{array}$ & $\begin{array}{c}P \\
\text { değerleri }\end{array}$ \\
\hline Yaş (yıl) & $29.99 \pm 5.54$ & $29.88 \pm 5.91$ & 0.860 \\
\hline İnfertilite süresi (yıl) & $6.62 \pm 4.47$ & $6.06 \pm 3.79$ & 0.247 \\
\hline Bazal FSH $(\mathrm{mIU} / \mathrm{mL})$ & $6.19 \pm 1.87$ & $5.87 \pm 1.81$ & 0.876 \\
\hline Bazal LH $(\mathrm{mIU} / \mathrm{mL})$ & $6.32 \pm 2.04$ & $6.41 \pm 1.92$ & 0.098 \\
\hline Bazal E $(\mathrm{ng} / \mathrm{m})$ & $45.43 \pm 15.09$ & $50.61 \pm 16.53$ & 0.687 \\
\hline Bazal Prolaktin $(\mathrm{ng} / \mathrm{mL})$ & $13.98 \pm 5.40$ & $13.42 \pm 5.61$ & 0.366 \\
\hline Bazal TSH $(\mathrm{uIU} / \mathrm{mL})$ & $2.30 \pm 0.79$ & $2.73 \pm 0.85$ & 0.733 \\
\hline Total GND doz kullanımı & $770.98 \pm 166.67$ & $812.25 \pm 175.57$ & 0.063 \\
\hline Endometrial kalınlık $(\mathrm{mm})$ & $8.59 \pm 1.43$ & $8.28 \pm 1.36$ & 0.055 \\
\hline
\end{tabular}
olarak kabul edilmiștir. 
IUI tedavisinin gebelik sonuçları üzerine olan etkisi incelendiğinde Oİ sonrası her iki grupta da 2 adet pre-ovulatuar folikül geliştirildiği TVUSG ile görüldü. $\beta$-hCG test pozitifliği 36 . Saatte IUI yap1lan hastaların \%21,6'sında izlenirken, 42. Saatte IUI yapilan hastaların \%14,7'sinde izlendi $(\mathrm{p}=0,129)$. 36. Saatte IUI yapılanların $\% 15,8$ 'i canlı doğum yapmışken, 42 . Saate IUI yapılanların \%11,8'i canlı doğum yapmıştı. Her ne kadar 36. Saate IUI yap1lanların hem $\beta$-hCG test pozitifliği hem canlı dogum oranlar1 42. Saate IUI yapilanlara göre daha fazla olsa da aradaki fark istatistiksel anlamlılığa ulaşamamıştır ( $p=0.129, p=0.313)$. Gruplar arasında spontan abort oranları arasinda da fark izlenmemiştir ( $\mathrm{p}=0.258$ ) (Tablo 2).

Tablo 2: 36. Saatte uygulanmış IUI sonuçları ile 42.saatte uygulanmış IUI sonuçlarının karşilaştırılması.

\begin{tabular}{|c|c|c|c|}
\hline & $\begin{array}{l}\text { IUI 36. saatte } \\
(\text { Sayl }=348)\end{array}$ & $\begin{array}{l}\text { IUI 42. saatte } \\
(\text { Say1 }=102)\end{array}$ & $\begin{array}{c}P \\
\text { değerleri }\end{array}$ \\
\hline $\begin{array}{l}\text { Toplam pre-ovulatuar } \\
\text { folikül sayısı }\end{array}$ & $2(1-3)$ & $2(1-3)$ & 0.341 \\
\hline $\begin{array}{l}\beta \text {-hCG test } \\
\text { pozitifliği }\end{array}$ & $75(21.6 \%)$ & $15(14.7 \%)$ & 0.129 \\
\hline $\begin{array}{l}\text { Canlı doğum } \\
\text { sayıs1 }\end{array}$ & $55(15.8 \%)$ & $12(11.8 \%)$ & 0.313 \\
\hline $\begin{array}{l}\text { Spontan abort } \\
\text { sayis1 }\end{array}$ & $20(5.7 \%)$ & $3(2.9 \%)$ & 0.258 \\
\hline
\end{tabular}

Değerler ortanca (min-max) ve yüzde (\%) olarak verilmiş ve $\mathrm{p}<0.05$ olarak kabul edilmiştir.

\section{TARTIŞMA}

Ovulasyon indüksiyonu yapılarak IUI planlanan hastalarda hCG sonras1 yap1lacak IUI'1n zamanlaması gebelik oluşma şansını çok etkilemektedir. HCG sonrasi 36 . Saatte IUI yapmak en optimal davranıştır ancak sperm hazırlığı, ulaşımı ve hatta klinik yoğunluk sebebi ile IUI zamanlamasında gecikmeler yaşanabilmektedir. Biz de bu çalışmamıda ovulasyon indüksiyonu uyguladığımız açıklanamayan infertil hastalarımızda IUI uygulaması hCG sonrasi optimal zaman olan 36. Saate yapilanlar ve 42. Saatte yapılanların klinik gebelik sonuçlarını karşılaştırdık ve 6 saat gecikmenin sonuçları değiştirmediğini bulduk.

IUI sikluslarında oluşacak gebelik sonuçlarındaki iyileşme ile ilişkili faktörlerin değerlendirilmesi yıllarca yoğun bir şekilde çalışılmıştır. $\mathrm{Bu}$ faktörlerin bazıları kadın yaşı, infertilite süresi, endometrial reseptivite, matür folikül sayısı, çeşitli semen hazırlama teknikleri, sperm hareketliliğgi, sperm konsantrasyonu ve sperm morfolojisidir (10, 11). Yine tartıșılan etkenlerden biri de uyarılmıș sikluslarda inseminasyonun doğru zamanlamasıdır, böylece fertilizasyon en optimum zamanda gerçekleşir ve gebelik şansı artar.

Natural ve uyarılmış sikluslarda ovulasyonun zamanlaması farklıdır ve inseminasyon yapılırken buna dikkat etmek gerekir. Dünya Sağlık Örgütü raporuna göre natural menstrüasyon sikluslarında ovulasyon, LH'de belirgin bir artıştan 24-56 saat (ortalama 32 saat) sonra gerçekleşir (12). Uyarılmış sikluslarda ise ovulasyon hCG enjeksiyonundan yaklaşı 36-48 saat sonra meydana gelir ve bu süreç stimulasyon için kullanılan ilaçların türü ve miktarından etkilenir (13). GND kullanılarak OI uygu- lanmış hastaların yaklaşık \%24'ünde prematür LH yükselmesi gösterilmiştir (5). Bu yüzden IUI sikluslarında gebelik olasılığını en üst düzeye çıkarmak için en uygun inseminasyon zamanını bulmak hala zorluk oluşturmaktadır.

Farklı zamanlarda yapılan IUI uygulamalarında gebelik oranlarını karşılaştıran bir çalışmada IUI uygulamas 36 saatten önce yapılanlarda gebelik oranı $\% 5$ bulunmuşken, 38 saat ve sonrasında yapılan IUI'lerde ise gebelik oran1 \%20 olarak bulunmuştur ve 36 saatten önce IUI uygulanmaması gerektiği üzerinde durulmuştur (14). Başka bir çalışmada hCG enjeksiyonundan 24 saat sonra ve 36 saat sonra yapılan IUI'ler gebelik sonuçları açısından karşılaştırılmış ve arada bir fark olmadığ1 bulunmuştur (15). hCG'nin 24. Saatinde ve 36. Saatinde yapılan IUI'leri karşılaştıran bir çalışmada gebelik sonuçlarının PCOS grubunda değişmediğini ancak açıklanamayan infertil hastaların erken IUI'dan fayda görebileceği üzerinde durulmuştur (16). Bu çalışmada açıklanamayan infertillerde bozuk sperm fertilizasyon kapasitesinin erken yapılan IUI ile iyileştirilebileceği savunulmuştur. 38-40. Saate geciktirilmiş IUI uygulamasının gebelik oranlarını artırdığını öne süren çalışmada vardır (17).

Ovulasyona yakın inseminasyon uygulamas1, orta dereceli infertil hastalarda gebelik başarısını artırabilir. Spermatozoanın female reproduktif sistemde yaklaşık 1,4 gün hayatta kalabilmesine rağmen, oositlerin sadece 12-16 saat boyunca döllenebilme yeteneği olduğu bilinmektedir. Ayrıca, sperm sayısının ve motilitesinin az olmas 1 da spermin canlı kalım süresini azaltabilmektedir (18). Çalışmamızda 42. Saate IUI yapılmış hastalarda $\beta$-hCG test pozitifliği ve canlı doğum oranları 36. Saatte IUI yapılmış hastalara kıyasla daha düşük çıksa da aradaki fark istatistiksel anlamlılığa ulaşmadığı için 6 saatlik bir gecikmenin IUI uygulamalarında gebelik sonuçlarını değiştirmeyeceğini düşünüyoruz. Çalışmamızın limitasyonlarından biri inseminasyon için hazırlanan sperm örneklerinde sperm sayısı ve morfolojisine göre ayırım yapmadan nakil işlemi gerçekleştirilmiş olmasıdır. Bu durumda değişen sperm hareketliliği ve morfolojisi gebelik sonuçlarını etkileyebilmektedir. İleride yapılacak çalışma gruplarında sperm parametreleri standardize edilip IUI zamanlamaları karşılaştırıldığında daha bağımsiz sonuçlara ulaşılabilecektir.

Açıklanamayan infertilite sebebi ile GNDler ile Oİ yapılmış sikluslarda hCG enjeksiyonun 42 . Saatinde IUI uygulamas1, 36. Saatte IUI uygulamasindan farklı $\beta$-hCG test pozitiflikleri ve canlı gebelik oranlarına sebep olmamaktadır. Spermin hazırlanması, transferi veya muayene yoğunluğu dolayısıyla IUI uygulaması 6 saat geciktirilmiş hastaların gebelik sonuçları kötüleşmemektedir.

\section{KAYNAKLAR}

1. Dodson WC, Haney AF. Controlled ovarian hyperstimulation and intrauterine insemination for treatment of infertility. Fertil Steril 1991; 55: 457-467.

2. Duran H, Mahmood M, Kruger T, Oehninger S. Intrauterine insemination: a systematic review on determinants of success. Hum Reprod Update 2002; 8: 373-384. 
3. ESHRE Capri Workshop Group. Intrauterine insemination. Hum Reprod Update 2009; 15: 265 e77.

4. Ragni G, Somigliana E, Vegetti $W$. Timing of intrauterine insemination: Where are we? Fertil Steril 2004; 82: 25-26.

5. Cohlen BJ, te Velde ER, van Kooij RJ, Looman CW, Habbema JD. Controlled ovarian hyperstimulation and intrauterine insemination for treating male subfertility: A controlled study. Hum Reprod 1998; 13: 1553-1558.

6. Jarvela IY, Tapanainen JS, Martikainen H. Improved pregnancy rate with administration of hCG after intrauterine insemination: A pilot study. Reprod Biol Endocrinol 2010; 8 . 18.

7. Aydin Y, Hassa H, Oge T, Tokgoz VY. A randomized study of simultaneous $h C G$ administration with intrauterine insemination in stimulated cycles. Eur J Obstet Gynecol Reprod Biol 2013; 170: 444-448.

8. Tonguc E, Var T, Onalan G, Altinbas S, Tokmak A, Karakaș N, Gulerman C. Comparison of the effectiveness of single versus double intrauterine insemination with three different timing regimens. Fertil Steril. 2010; 94: 1267-1270.

9. Cooper TG, Noonan E, von Eckardstein S. World Health Organization reference values for human semen characteristics. Hum Reprod Update 2010; 16: 231-245.

10. Merviel P, Heraud MH, Grenier N, Lourdel E, Sanguinet $P$, Copin H. Predictive factors for pregnancy after intrauterine insemination (IUI): An analysis of 1038 cycles and a review of the literature. Fertil Steril 2010; 93: 79-88.

11. Demir B, Dilbaz B, Cinar O, Karadag B, Tasci Y, Kocak $M$, Dilbaz $S$, Goktolga U. Factors affecting pregnancy outcome of intrauterine insemination cycles in couples with favourable female characteristics. J Obstet Gynaecol 2011; 31: 420-423.

12. World Health Organization, Task Force on Methods for the Determination of the Fertile Period, Special Programme of Research, Development and Research Training in Human Reproduction. Temporal relationships between ovulation and defined changes in the concentration of plasma estradiol-17 beta, luteinizing hormone, follicle-stimulating hormone, and progesterone. I. Probit analysis. Am J Obstet Gynecol 1980; 138: $383-390$

13. Ghanem ME, Bakre NI, Emam MA, Al Boghdady LA, Helal AS, Elmetwally AG, Hassan M, Albahlol IA, Elzayat MM. The effects of timing of intrauterine insemination in relation to ovulation and the number of inseminations on cycle pregnancy rate in common infertility etiologies. Hum Reprod 2011; 26 : 576-583.

14. Lee J, Hwang S, Lee J, Yoo J, Jang D, Hwang K, Kim M. Effect of insemination timing on pregnancy outcome in association with female age, sperm motility, sperm morphology and sperm concentration in intrauterine insemination. J Obstet Gynaecol Res. 2018; 44: 1100-1106.

15. Lemmens L, Kos S, Beijer C, Brinkman JW, van der Horst FA, van den Hoven L, Kieslinger DC. Predictive value of sperm morphology and progressively motile sperm count for pregnancy outcomes in intrauterine insemination. Fertil Steril 2016; 105: 1462-1468.

16. Yumusak OH, Kahyaoglu S, Pekcan MK, Isci E, Cinar M, Tasci $Y$. Does intrauterine insemination timing matter for achieving pregnancy during ovulation induction using gonadotropins? A retrospective cohort study. J Chin Med Assoc. 2017; 80: $366-370$
17. Pryor JL, Kuneck PH, Blatz SM, Thorp C, Cornwell CE, Carrell DT. Delayed timing of intrauterine insemination results in a significantly improved pregnancy rate in female partners of quadriplegic men. Fertil Steril 2001; 76: 1130-1135.

18. Kosmas IP, Tatsioni A, Fatemi HM, Kolibianakis EM, Tournaye H, Devroey P. Human chorionic gonadotropin administration vs. luteinizing monitoring for intrauterine insemination timing, after administration of clomiphene citrate: A meta-analysis. Fertil Steril 2007; 87: 607-612. 